J. Perinat. Med.

3 (1975) 123

\title{
The effect of palliative surgery on the survival of central nervous system malformations
}

\section{Isabel Gal}

The Hatfield Polytechnic, Biology Department Hatfield, Hertfordshire, England

Received August 13, 1974. Accepted September 24, 1974.

In the past decade in Great Britain, babies born with central nervous system malformations received active surgical therapy, regardless of the clinical prognosis of the defect. In this way many severely deformed patients were kept alive, which presents serious problems to the disabled persons themselves, their family as well as to the medical and social services of the country. As a consequence we are entering a new phase, when election of cases for surgery is again adrocated (Lorber [2], LaURence [1]). However this suggestion did not gain uniform support, based partly on ethical consideration and partly because of the many problems which arise for the patient and for those engaged in their care (MAC-KEITH [3]). Whilst the former authors are referring to the primary closure of the spinal defect, the latter is reviewing the problem of the secondary complications point of view.

Hydrocephalus is not only the most frequent but probably the most troublesome complication of the condition. In an attempt to relieve the intracranial pressure, a wide range of therapeutic measures were developed, out of which the initial ones produced little achievements, whereas the more recent ones gave satisfactory results in most of the cases. However, it is as yet not clarified whether this operation extends the patient's life or just reduces their suffering.

\section{Material}

In the course of a retrospective survey, I gathered information regarding this problem, while studying the patients (or their records) suffering from central nervous system malformations, and who were admitted to Queen Mary's Hospital for Children, Carshalton, Surrey, between the years of 1940-1965. During this period 70 cases were admitted with the above malformation, including 44 cases of hydrocephalus alone,

\section{Curriculum vitae}

ISABEL GAL obtained ber Doctor of Medicine and Specialist in Cbildren's Diseases Degree at the Faculty of Medicine, University of Budapest, Hungary'. After emigrating to England she re-qualified at the University of Edinburgb \& Glasgow.

Sbe started ber medical career as a pediatrician at the Bokay Hospital for Cbildren, Budapest, and continued it at tbe West Middlesex Hospital,

London. Since 1964 she bas been engaged in full time research on buman reproduction, witb special reference to congenital malformations. Tbese studies were undertaken at Queen Marj's Hospital for Cbildren, Carsbalton, at the Institute of Cbild Health (Great Ormond Street Hospital) and at the Institute of Obstetrics and G'necology' (Queen Cbarlotte's Maternity Hospital) London. At present sbe is a Reader in Teratology' at the Department of Biology at the Hatfield Poljtecbnic.

Her main clinical researcb interest is the role of vitamin- $A$ in buman reproduction and teratology.

21 cases of spinal defect with hydrocephalus and 5 cases of spinal defect alone. Some of these patients had surgical therapy while the others did not. Their distribution mainly represents the developmental phases of the management of the condition advocated during this long lasting study. Medical selection or the parents preference for operation did not seem to have had significant influence. This group of patients presents a unique material for studying the effect of palliative surgery, because being in the same environment all cases have been provided with similar standards of care.

\section{Method and results}

Although detailed information was collected regarding the patients' genetic and environmental background, as well as on the clinical progress 


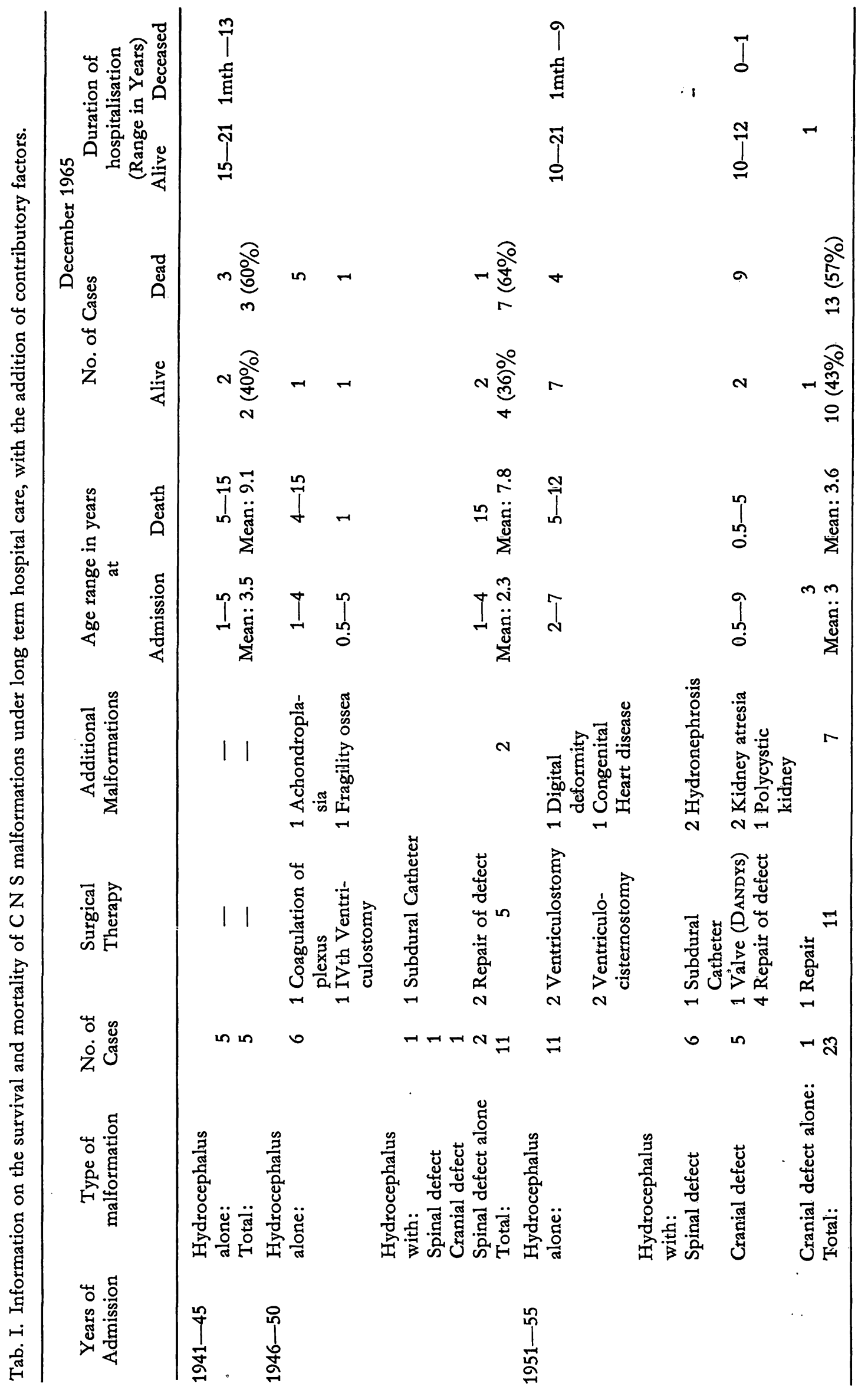




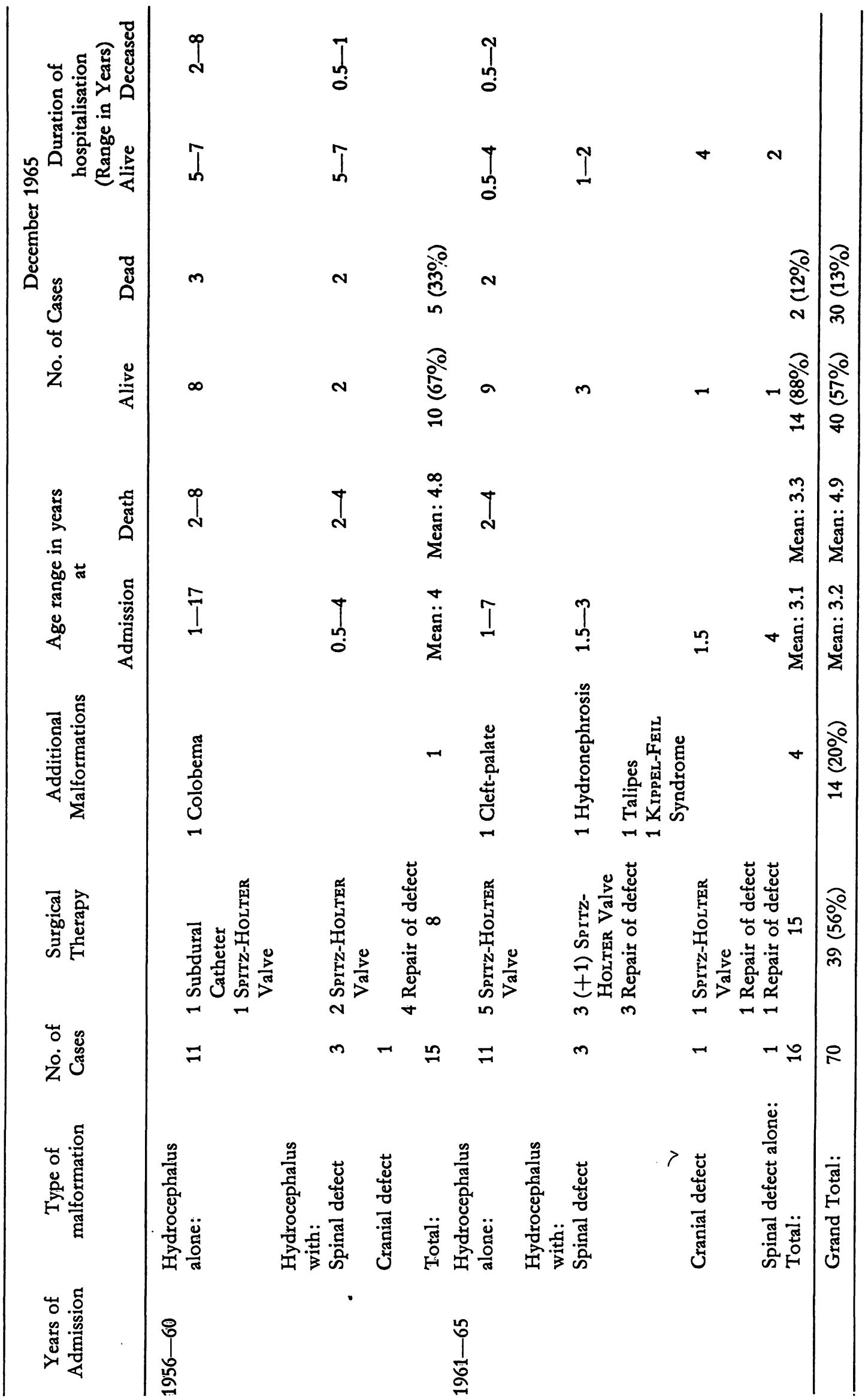


(data available from the author) in the following only those aspects which are relevant to the present problem will be described:

Presentation of a survey of 25 years duration is a complicated matter, particularly when major changes happened in the management of the conditions. Therefore the information about the patients (who were admitted within 5-yearly intervals) was grouped together and sub-divided into 3 clinical categories as shown in Tab. I.

The data have been evaluated for the whole and also for the separate groups. For the sake of more accurate information the age at admission and at death are expressed in range and means. Since the survival and mortality rates may be affected by therapeutic measures and additional malformations, these were also included in the same Table. The duration of hospitalisation has been shown separately for the deceased patients and for the ones surviving at the end of the study (31. 12. 1965).

An increase in the number of admissions occurred after 1950. This may be related to the improved survival rate of neural-tube malformations, consequent on the introduction of early surgery and the use of antibiotics, but it is also possible the newly established National Health Service with its provision of free hospital treatment could have contributed to this change.

The mean age at admission for the total group was 3.2 years, and the 5-yearly intervals group also showed close agreement $(3.5,2.3,3,4,3.1$ years respectively), in spite of the wide variation which has been found in individual cases. It is important to emphasize that the age at long term hospital admission is not always closely related to the severity of conditions, because it is often determined by other factors (e. g. socioeconomic conditions, needs of management, etc.). At the end of the survey 40 patients were alive (57\%) and 30 deceased (43\%). In a long lasting study it is difficult to assess the accuracy of representation of these figures. Since most of the cases survived their most crucial stage of life on admission (only $6 \%$ were under 1 year), the mortality rate in our study is lower than those reported in other studies. For the total group the mean age at death was 4.9 years, and in the 5-yearly intervals it was
9.1 : $7.8: 3.6: 4.8:$ and 3.3 years. Individual cases showed an even wider variation in the range of $0.5+15$ years. Apparently, spina-bifida cases died relatively earlier than those who were suffering from hydrocephalus alone.

Investigation into the duration of hospitalisation showed that the deceased patients stayed an average of 4.9 years in the hospital, ranging from 3 days to 13 years. Surviving patients spent an average of $5^{1 / 2}$ years in the hospital, but this varied considerably by individual cases such as 5 patients were hospitalised for between $15-20$ years, and 2 patients for over 20 years by the end of the survey. The above figures might indicate the social need of those cases who require permanent institutional care (following modern surgery the estimated figure is about $10 \%$ of all treated cases).

Surgical treatment has only been provided for patients who were admitted after the year of 1946. Operative measures at the individual stages of the study correspond with the developmental phases of surgical management of CNS mal-. formations. The total number of operations are relatively few, in comparison with the therapeutic measures undertaken at present. The proportion of the surgically treated cases increases in the latter stages of the study.

Out of the 65 cases of hydrocephalus only 26 ( $40 \%)$ have had surgical therapy to relieve the intracranial pressure. The applied technique, in most of these cases, was less effective than the SPITZ-Holter valve, but the severe expansion of the head has been controlled to a certain extent. The head circumference of non-operated cases occasionally reached as much as 76,89 or 102 centimeters.

The spinal defect was corrected in a higher proportion. Out of the 16 cases of spina-bifida, 16 patients $(61 \%)$ were operated on. The remaining cases had skin-covered lesions.

Since the main purpose of the study is to evaluate the effect of palliative surgery on the survival rate, the patients belonging to the same clinical category have been sub-divided into those who were operated on and those who were not. Tabs. II $\mathrm{A}$ and II $\mathrm{B}$ show that the mean age at death was unaffected by palliative surgery. 
Tab. II A. Mean and median age at death of operated and non-operated hydrocephalus alone cases.

\begin{tabular}{lcccccc}
\hline $\begin{array}{c}\text { Years of } \\
\text { Admission }\end{array}$ & No. of Cases & $\begin{array}{c}\text { Operated group } \\
\text { age at death (years) } \\
\text { Mean }\end{array}$ & Median & $\begin{array}{c}\text { No. of } \\
\text { Cases }\end{array}$ & $\begin{array}{c}\text { Non-operated group } \\
\text { age at death (years) } \\
\text { Mean }\end{array}$ & Median \\
\hline $1941-45$ & 2 & 10 & 10 & 3 & 9 & 7 \\
$1946-50$ & 2 & 3.7 & 3.7 & 3 & 4 & 2.5 \\
$1951-55$ & 2 & 3.25 & & 3 & 6.75 & 8.75 \\
$1956-60$ & & & & & 8 \\
$1961-65$ & 6 & 5.6 & 3.25 & 11 & 5.32 & 5.5 \\
\hline Total & 6 & &
\end{tabular}

Tab. II B. Mean and median age at death of operated and non-operated hydrocephalus cases in association with spinal defect.

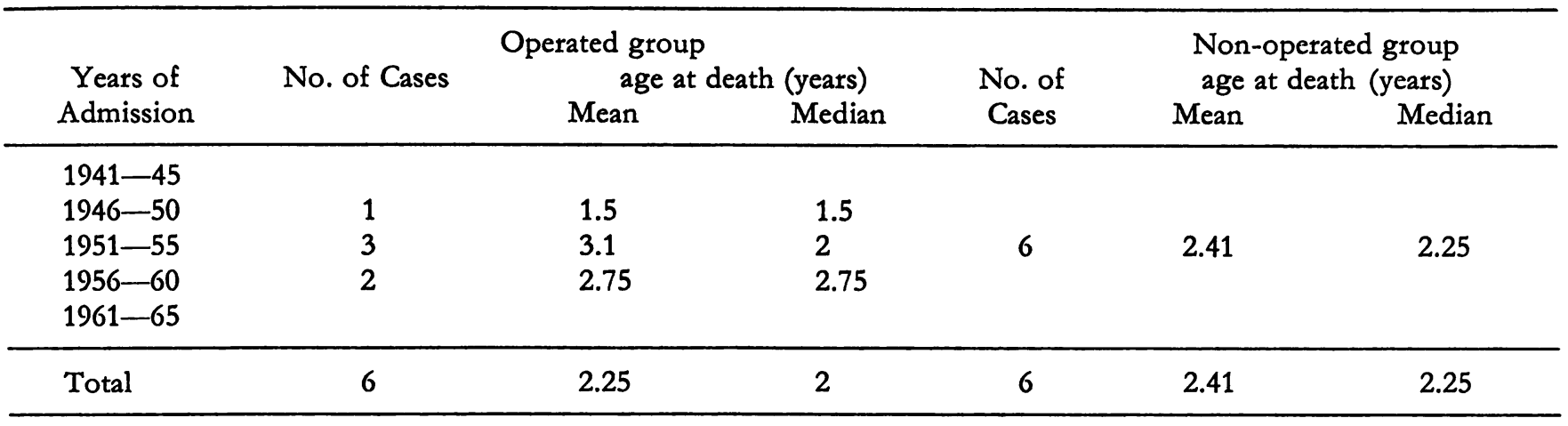

Secondary complications were also studied in relation to operations. Tabs. III A and III B show that major complications like paralysis, blindness, epilepsy occurred more frequently in non-operated cases. Besides these, many unusual clinical features have been encountered which could possibly develop because of the long survival of our patients.

Attention has been paid to additional malformations because they might also affect the length of survival (listed in detail in Tab. I). In the group with hydrocephalus only, $15 \%$ of cases had other malformations ( 1 cleft palate, 1 digital deformity, 1 congenital heart disease, 1 fragility ossea and 1 achondroplasia). In the spinal defect group, $28 \%$ of cases suffered from other anomalies ( 1 talipes, 2 unilateral kidney atresia, 2 hydronephrosis and 1 KIPpEL-FeIL syndrome). According to our findings the survival of our cases has only been affected by renal tract malformations.

\section{Conclusion}

The study suggests that the survival of patients suffering from hydrocephalus either alone or
Tab. III A. Secondary complications in hydrocephalus alone cases according to operation.

\begin{tabular}{lccc}
\hline \multicolumn{1}{c}{$\begin{array}{c}\text { Secondary } \\
\text { Complications }\end{array}$} & Total & Operated & $\begin{array}{c}\text { Non- } \\
\text { Operated }\end{array}$ \\
\hline Various degree of & & & \\
Paralysis & 17 & 6 & 11 \\
Blindness & 13 & 3 & 10 \\
Epilepsy & 12 & 4 & 8 \\
\hline
\end{tabular}

Tab. III B. Secondary complications in spina-bifida cases in association with hydrocephalus (closure of the defect is not included in the above operations).

\begin{tabular}{lccc}
\hline \multicolumn{1}{c}{$\begin{array}{c}\text { Secondary } \\
\text { Complications }\end{array}$} & \multicolumn{3}{c}{ Number of Cases } \\
Ootal & Operated & $\begin{array}{c}\text { Non- } \\
\text { Operated }\end{array}$ \\
\hline Various degree of & 6 & 3 & 3 \\
Paralysis & 3 & & 3 \\
Blindness & 1 & & 1 \\
Epilepsy & & \\
\hline
\end{tabular}

in combination with a mild degree of spinal defect is affected by the provision of nursing care. 
Palliative surgical therapy to relieve the symptoms of hydrocephalus does not alter the life-span significantly, but prevents the development of secondary complications considerably.

\section{Summary \\ Patients suffering from hydrocephalus alone or in rcm- bination with spinal defect were investigated in this retro- spective study. The cases were grouped to those who did not have any treatment to relieve the symptoms of hydro- cephalus and to those who receive certain palliative therapy (Tab. I). Comparisons were made between the groups regarding the life-span and the incidence of secondary complications. The life-span showed a close agreement}

If this observation could be substantiated on a larger scale then the above palliative therapy could be exercised even by those workers who believe in the selection of cases for surgical treatment of neural-tube malformations.

within the groups, but the occurrence and the severity of secondary complications were found to be less in the treated group (Tabs. II-III).

While the reasons are acceptable which are given to select the patients for the initial closure of the spinal defect there seems to be no justification in with-holding palliative surgery for the treatment of hydrocephalus.

Keywords: Hydrocephalus, palliative therapy effect, secondary complications, survival.

\section{Zusammenfassung}

Untersuchungen über den Einfluß von PalliativOperationen auf die Überlebensrate von Kindern mit zentralnervösen Fehlbildungen

In einer retrospektiven Studie wurden Patienten untersucht, die an einem Hydrozephalus mit oder ohne eine spinale Mißbildung litten. Die Fälle wurden in 2 Gruppen aufgeteilt, einmal jene, die keinerlei symptomatische Behandlung des Hydrozephalus erhalten hatten, und jene, bei denen gewisse Palliativ-Eingriffe vorgenommen worden waren (Tab. I).

Der Vergleich der beiden Gruppen bezog sich auf die Lebensspanne und die Häufigkeit von Sekundärkompli-

Schlüsselwörter: Hydrozephalus, Nachuntersuchungen, palliativer Therapieeffekt, Sekundärkomplikationen, Überlebensrate.

\section{Résumé}

Effet de la chirurgie palliative sur la survivance de malformations du système nerveux central

Cette étude rétrospective porte sur l'examen de patients souffrant d'hydrocéphalie seule ou avec défaut spinal. Les cas ont été répartis en deux groupes selon qu'ils avaient réçu ou non un certain traitement thérapeutique palliatif. Des comparaisons ont été établies quant à la durée de la vie et à l'incidence de complications secondaires (Tab. I).

kationen. Die Überlebensdauer zeigte eine enge Übereinstimmung in beiden Gruppen, wohingegen das Auftreten und die Schwere der sekundären Komplikationen in dem behandelten Kollektiv geringer war (Tabs. II-III). Während die Gründe für den sofortigen Verschluß eines spinalen Defektes und die Voraussetzungen für die Auswahl dieser Patienten annehmbar sind, scheint es keine Rechtfertigung für die Aufrechterhaltung der Palliativ-Chirurgie in der Behandlung des Hydrozephalus zu geben.

La durée de la vie a révélé des valeurs concordantes à l'intérieur des groupes, mais l'apparition et la gravité des complications secondaires ont été inférieures dans le groupe ayant reçu un traitement palliatif (Tabs. II-III).

Tandis qu'on peut admettre les raisons indiquées pour sélectionner les patients en vue d'une obturation initiale du défaut spinal, il ne semble pas justifié de ne pas procéder à un traitement chirurgical palliatif pour l'hydrocéphalie.

Mots-clés: Complications secondaires, effet thérapeutique palliatif, hydrocéphalie, survivance.

\section{Acknowledgement}

This work has been supported by a grant from the Society for Mentally Handicapped Children.

I am grateful to Dr. B. KIrmaN of Queen Mary's Hospital, Carshalton, Surrey, for his help and encouragement, and to many other colleagues for permitting to study the patients under their care.

\section{Bibliography}

[1] Laurence, K. M.: The effect on the family of the birth of a child with spina bifida. 1st Symposium of European Teratology Society, Cardiff, April 1971
[2] Lorber, F.: Results of Treatment of Myelomeningocele. Dev. Med. Child Neurol. 13 (1971) 279

[3] MacKeith, R. C.: A new look at spina bifida aperta. Dev. Med. Child Neurol. 13 (1971) 277

Isabel Gal, MD. LRCP. LRCS. LRFPS.

The Hatfield Polytechnic Biology Department Hatfield, Hertfordshire

England 